\title{
Factor Structure of Urdu Version of the Flourishing Scale
}

\begin{abstract}
Fahad R. Choudhry ${ }^{1,2 *}$, Yaser M. Al-Worafi ${ }^{3}$, Bushra Akram ${ }^{4}$, Mirza A. Ahmed ${ }^{5}$, Muhammad Anwar ul Haq ${ }^{5}$, Tahir Mehmood Khan ${ }^{6,7}$, Inayat U. Rehman ${ }^{8}$, Nadia Barki ${ }^{2}$, Khadeeja Munawar ${ }^{1,9 *}$, Anila Kamal ${ }^{2}$, Yaman W. Kassab ${ }^{10}$, Faizah S. Bakrin ${ }^{11}$ and Karen J. Golden ${ }^{1}$

${ }^{1}$ Department of Psychology, Jeffrey Cheah School of Medicine and Health Sciences, Monash University Malaysia, Bandar Sunway, Malaysia, ${ }^{2}$ National Institute of Psychology, Quaid-i-Azam University, Islamabad, Pakistan, ${ }^{3}$ Clinical Pharmacy Department, College of Pharmacy, Ajman University, Ajman, United Arab Emirates, ${ }^{4}$ Department of Psychology, University of Gujrat, Gujrat, Pakistan, ${ }^{5}$ Department of Management Sciences, University of Gujrat, Gujrat, Pakistan, ${ }^{6}$ Department of Pharmacy, Abasyn University, Peshawar, Pakistan, ${ }^{7}$ Institute of Pharmaceutical Science, University of Veterinary and Animal Sciences, Lahore, Pakistan, ${ }^{8}$ Department of Pharmacy, Abdul Wali Khan University, Mardan, Pakistan, ${ }^{9}$ Department of Psychology, University of Wah, Rawalpindi, Pakistan, ${ }^{10}$ Department of Hospital and Clinical Pharmacy, Cyberjaya University College of Medical Sciences, Cyberjaya, Malaysia, ${ }^{11}$ School of Pharmacy, KPJ Healthcare University College, Nilai, Malaysia
\end{abstract}

OPEN ACCESS

Edited by:

Nuno Conceicao,

Universidade de Lisboa, Portugal

Reviewed by:

Alessio Gori,

Università degli Studi di Firenze, Italy Mila Vulchanova,

Norwegian University of Science and

Technology, Norway

*Correspondence:

Fahad R. Choudhry

fahad.riaz.psy@gmail.com

Khadeeja Munawar

khadeeja.munawar@uow.edu.pk

Specialty section:

This article was submitted to

Clinical and Health Psychology, a section of the journal

Frontiers in Psychology

Received: 09 November 2017

Accepted: 31 July 2018

Published: 19 September 2018

Citation:

Choudhry FR, Al-Worafi YM, Akram B,

Ahmed MA, Anwar ul Haq M,

Khan TM, Rehman IU, Barki N,

Munawar K, Kamal A, Kassab YW,

Bakrin FS and Golden KJ (2018)

Factor Structure of Urdu Version of the Flourishing Scale.

Front. Psychol. 9:1513.

doi: 10.3389/fpsyg.2018.01513
Background: A great deal of research has been carried out on the assessment of the eudaimonic perspective of psychological well-being and the hedonic perspective of subjective well-being. The Flourishing Scale (FS) has been extensively used in research and practice, as it assesses the fundamental aspects of social psychological functioning. Nevertheless, the psychometric properties of Urdu versions of eudaimonic measures, such as the FS, have not yet been ascertained. The translation and validation of the FS in the Urdu language was not available, and hence this study was planned with the aim to validate the Urdu version of the FS.

Methods: We assessed the psychometric properties of the FS in a sample of adults aged 18 years and above in Pakistan $(N=130)$ using exploratory factor analysis based on principal component analysis with varimax rotation and confirmatory factor analysis.

Results: The exploratory factor analysis confirmed the unidimensional nature of the 8-item FS. We assessed that the Urdu version of the FS showed a high internal consistency reliability $(\alpha=0.914)$ with a significant intraclass correlation coefficient (ICC), $p<0.001)$. In our study, the Kaiser-Mayer-Olkin value was 0.915 with a chi-square test value $\left(\chi^{2}\right)$ of 637.687, and Bartlett's test of sphericity was significant $(d f=28, p<0.001)$. The intraclass correlation coefficients (ICCs) at test-retest for all domains were statistically significant $(p<0.001)$ and showed excellent agreement for all the items. The revised confirmatory factor analysis revealed a good-fit model, but with item 8- "People respect me"-removed due to its lower factor loading.

Conclusions: The findings suggest that the FS is a psychometrically sound instrument for assessing social psychological functioning among adults in Pakistan. Therefore, the validated Urdu version of the FS may be used in future studies of well-being in clinical psychology and positive psychology.

Keywords: psychometric properties, confirmatory factor analysis, mental well-being, psychological well-being, social psychological functioning, flourishing, Pakistan, positive psychology 


\section{INTRODUCTION}

In recent decades, psychological well-being and subjective wellbeing have become a center of attention for researchers (Ryff, 1989; Diener et al., 1999; Diener and Biswas-Diener, 2008; Tong and Wang, 2017). Mental well-being, which encompasses both hedonic and eudaimonic perspectives on well-being, is considered a multifaceted construct that has undergone comprehensive and extensive empirical exploration (SchotanusDijkstra et al., 2016). The hedonic perspective refers to the emotional or "feeling good" dimension of well-being, and the eudaimonic perspective refers to psychological functioning or the "living well" dimension of well-being (Diener, 1984; Lee and Ishii-Kuntz, 1987). Subjective well-being is defined as comprising both affective and cognitive appraisals of one's quality of life (Diener, 1984; Tong and Wang, 2017). Because of a lack of consensus on the definition of subjective well-being, it has been the subject of ongoing empirical investigation (Bradburn, 1969; Diener, 1984; Diener et al., 1985, 2009; Hills and Argyle, 2002). Usually research studies based on the hedonic perspective of subjective well-being have used single-item or brief measures, such as the Satisfaction with Life Scale (Diener et al., 1985), the Subjective Happiness Scale (Lyubomirsky and Lepper, 1999), and the Positive and Negative Affectivity Scale (Watson et al., 1988). Despite the fact that these measures have undergone extensive research and practice, they have been unable to fully capture the social and psychological well-being dimensions (SchotanusDijkstra et al., 2016).

The eudaimonic perspective and its core aspects have recently been the focus of growing research attention (Schotanus-Dijkstra et al., 2016). Five core dimensions of social well-being were identified based on sociological and social psychological theories (Corey Lee, 1998). Likewise, six core dimensions of psychological well-being were identified based on an extensive review of humanistic, existential, and developmental theories (Ryff, 1989). All the social and psychological core aspects of well-being are present in the Mental Health Continuum-Short Form (MHCSF), which also assesses hedonic well-being (Keyes, 2005; Keyes et al., 2008). Other comprehensive but generic measures for assessing well-being are the WHO-Five Well-being Index (Bech, 1999) and the Warwick-Edinburgh Mental Well-being Scale (Tennant et al., 2007).

Flourishing has been shown to be measured by the constructs of meaning and achievement as well as by an affective component (Bradburn, 1969; Diener, 1984; Watson et al., 1988; Seligman, 2011; Tong and Wang, 2017). According to research findings of an early study by Diener (1984), subjective well-being comprises life satisfaction and positive and negative affect. Other instruments developed by researchers to assess a variety of emotions and feelings include the Positive and Negative Affect Schedule (Watson et al., 1988), the Affect Balance Scale (Bradburn, 1969), and the Hedonic Balance Scale (Schimmack et al., 2002). There is a need for more exploratory empirical studies to better understand the concepts, definitions, and measurement of well-being (Busseri and Sadava, 2011; Tong and Wang, 2017). Relatedly, there is a need for such instruments that focus solely on the measurement of the core dimensions of the eudaimonic perspective (Schotanus-Dijkstra et al., 2016). Thus, a brief and comprehensive Flourishing Scale (FS) has recently been designed that is based on the humanistic and eudaimonic wellbeing perspectives (Diener et al., 2009; Schotanus-Dijkstra et al., 2016).

According to the majority of researchers, flourishing is a state in which high levels of subjective well-being as well as social psychological well-being are attained (Keyes, 2002; Seligman, 2011; Hone et al., 2013; Schotanus-Dijkstra et al., 2016). The first version of this scale had 12 items and was called the Psychological Flourishing Scale (Diener et al., 2008). It was followed by a revised and final version having eight items called the Psychological Well-being Scale (Diener et al., 2009). As this name was similar to Ryff's Scales of Psychological Well-being (Ryff, 1989), the Psychological Flourishing Scale was renamed as the FS (Diener et al., 2009). Owing to the briefness, easiness of use, and completeness of the FS, it has been used in a variety of well-being intervention studies and clinical practice and translated into 17 languages (Schotanus-Dijkstra et al., 2016). Across many samples, the psychometric properties of the FS have been established (Diener et al., 2009; Hone et al., 2013; Silva and Caetano, 2013; Howell and Buro, 2014; Sumi, 2014; Tang et al., 2016).

The psychometric properties of the FS have been assessed and various validated versions have been developed, such as versions in Portuguese, Japanese, Indian, Italian, Spanish, Croatian, Chinese, and in the language of the Netherlands (Silva and Caetano, 2013; Sumi, 2014; Duan and Xie, 2016; SchotanusDijkstra et al., 2016; Checa et al., 2017; Giuntoli et al., 2017; Ramírez-Maestre et al., 2017; Singh et al., 2017; Tong and Wang, 2017; Vujčić et al., 2017; Hojabrian et al., 2018).

Through confirmatory or exploratory factor analysis, research studies found the FS to have a single factor and found adequate to excellent Cronbach alpha reliability values ranging from 0.78 to 0.95 (Schotanus-Dijkstra et al., 2016). The majority of past validation studies have also supported the convergent validity of the FS (Checa et al., 2017; Giuntoli et al., 2017).

The translation of the FS (See Appendix) into the Urdu language and validation have not been carried out. Considering that Urdu is a national language of Pakistan, this validation study will help researchers use the FS in their studies within Pakistan or administer the FS to Urdu-speaking population in other parts of the world. According to the BBC (2014), Urdu is spoken around the world by approximately 100 million people. While it is a national language of Pakistan, it is also understood and spoken in parts of India, Bangladesh, the Middle East, Nepal, and other countries where Pakistani communities have settled.

\section{MATERIALS AND METHODS}

Data for the present validation study were collected from January to April 2016 in Islamabad, the capital city of Pakistan. For recruiting participants, the study flyers were distributed in two academic institutes, four shopping malls, and six restaurants. No financial compensations were offered as this was not a funded project. Participants were informed that the collected data would be used only for research purposes, and they signed the written informed consent form. All participants agreed to 
voluntarily take part in the present study and completed the scale. Confidentiality of data was ensured, and anonymity of participants' identity was maintained.

\section{Participants}

In the present study, a sample of adults in Pakistan aged 18 years and above $(N=130)$ was recruited. Of these, 111 were males $(85.4 \%)$ and 19 were females (14.6\%). Ages of participants ranged from 22 to 55 years (Median $=28.50$ years, IQR $=24.75-$ 32.00). Only those participants who were able to answer the statements of the scale in Urdu were recruited. Participants having any serious psychiatric illness (e.g., schizophrenia, bipolar disorder) or medical condition (e.g., cardiovascular problems, diabetes, cancer, etc.) were excluded. In terms of education, $13.85 \%(n=18)$ had completed 6 years of education, $30.77 \%$ $(n=40) 12$ years of education, 6.92\% $(n=9) 15$ years of education, $16.92 \%(n=22) 16$ years of education, and $31.54 \%$ $(n=41) 18$ years of education. A majority of the participants$-67.69 \%(n=88)$-belonged to the Punjabi ethnic group of Pakistan.

\section{Sample Size}

Based on the ratio between the numbers of items in the scale to participants-that is 1:10-(Lai et al., 2013), the minimum sample size calculated was 80 participants. However, we recruited 130 participants for this study and at retest we had 119 participants.

\section{Instrument for Translation}

The FS was originally developed by Diener et al. (2009) and has eight dimensions that measured human functioning features. Previous studies have shown the adequate psychometric properties of the FS in various countries (Diener et al., 2010; Esch et al., 2013; Silva and Caetano, 2013; Hone et al., 2014; Sumi, 2014). For linguistic validation of the FS, the same eight dimensions were translated into Urdu according to the guidelines mentioned in the past studies (Guillemin et al., 1993; Wild et al., 2005).

To conduct forward translation, a panel of Urdu language experts (consisting of three persons) was invited for providing feedback regarding the exact translation of the English statements to Urdu. The purpose of inviting Urdu language experts was to help ensure that the tool could be easily understood by Urduspeaking people. When this phase was completed, the instrument was given to a native Urdu language speaker for finalizing an initial version of the FS. To reassess the appropriateness of the translation, this translated questionnaire was given to the linguistic department. Linguistic experts suggested a few minor grammatical changes. After incorporating those suggestions, forward translation of the FS was achieved and backward translation was started (Wild et al., 2005). The Urdu version of the FS went through backward translation by experts. This scale was ready for face validity testing after backward translation was achieved.

The Urdu version of the FS was administered to 10 local Urduspeaking Pakistanis as a pilot study for assessing face validity. The responses of these participants were not included in the final analysis of data. Necessary feedback and comments from the participants were noted down and the instrument was modified through mutual consensus. A practicing psychologist, with the qualification of Ph.D. in psychology and more than a decade experience of working in the field of psychology and research, performed content validity of the translated FS. The instrument was ready for further validity and reliability assessment after achieving content validity.

\section{Procedure}

Participants were approached randomly in the locations mentioned earlier to assess the psychological well-being of the general population and the scale items were presented in random order. Furthermore, there were no significant differences in the FS mean score between participants who completed the scale at the initial stage of the study and those who did so at the end of the study. To assess the reliability, the Urdu FS was administered to the same participants 4 weeks later. The administration of scale took $<15$ min.

\section{Statistical Analysis}

To conduct the analysis, we used SPSS version 20.0 (SPSS Inc., Chicago, IL). Normality was assessed using the ShapiroWilks test. Non-parametric tests were performed as the data was not normally distributed. To present the continuous and categorical variables, median and interquartile range, as well as number and frequency were used, respectively. Exploratory

TABLE 1 | Demographic characteristics of participants of the FS $(N=130)$.

\begin{tabular}{lc}
\hline Demographics & $\mathbf{N}(\%)$ \\
\hline GENDER & \\
Male & $111(85.4)$ \\
Female & $19(14.6)$ \\
AGE (YEARS) & \\
Median & 28.50 \\
[IQR] & {$[24.75-32.00]$} \\
EDUCATION & \\
\hline Primary level [6 years of education] & $18(13.85)$ \\
Secondary level [12 years of education] & $40(30.77)$ \\
College/Diploma [15 years of education] & $9(6.92)$ \\
Undergraduate [16 years of education] & $22(16.92)$ \\
Postgraduate [18 years of education] & $41(31.54)$ \\
ETHNICITY & \\
Punjabi & $88(67.69)$ \\
Pashtoon & $27(20.77)$ \\
Sindhi & $12(9.23)$ \\
Gilgit/Skardu & $14(10.77)$ \\
Others & $27(20.77)$ \\
PERCEIVED SOCIOECONOMIC STATUS & $51(39.23)$ \\
Lower-Middle & $33(25.38)$ \\
Middle & $2(1.53)$ \\
Middle-High & \\
\hline
\end{tabular}


factor analysis was performed to examine the construct validity of the FS. The eigenvalues were retained for a factor $>1$ because of their significant contribution in explaining the overall model variation. Furthermore, to assess the sampling adequacy, the Bartlett's test of sphericity and the Kaiser-Mayer-Olkin (KMO) were used. KMO values below 0.5 are considered "unacceptable"
(Kaiser, 1974); values that fall in the range of $0.5-0.7$ are considered "mediocre;" "good" values lie in the range of $0.7-$ 0.8 ; the range of $0.8-0.9$ gives "great" values, while values $>0.9$ are considered "superb" (Field, 2009). The Mann-Whitney $U$ test was conducted to determine the discriminative validity, between baseline and retest as well as between males and females
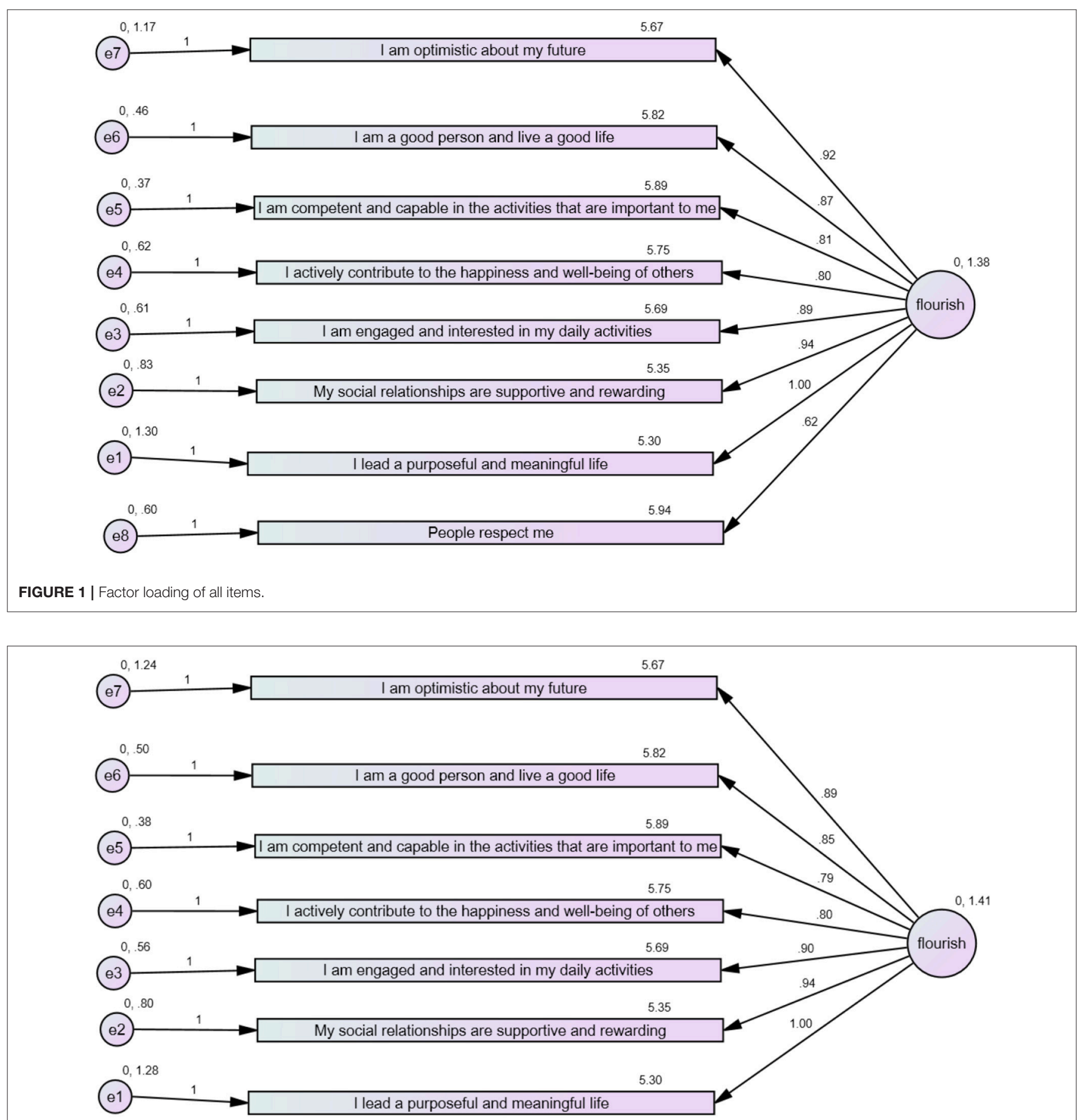

FIGURE 2 | Factor loading of all items except item 8. 
TABLE 2 | Scores of the Urdu FS among male and females.

\begin{tabular}{|c|c|c|c|c|c|c|c|c|}
\hline \multirow[t]{2}{*}{ Domains } & \multicolumn{2}{|c|}{ Males } & \multirow[b]{2}{*}{ Mean \pm SD } & \multicolumn{2}{|c|}{ Females } & \multirow[b]{2}{*}{ Mean \pm SD } & \multicolumn{2}{|c|}{ Mann-Whitney $U$-test } \\
\hline & Median & [IQR] & & Median & IQR & & z-score & $p$-value \\
\hline Purpose and meaning & 6.00 & {$[2.00]$} & $5.31 \pm 1.66$ & 6.00 & {$[2.00]$} & $5.26 \pm 1.59$ & -0.173 & 0.86 \\
\hline Supportive relationships & 6.00 & {$[1.00]$} & $5.28 \pm 1.46$ & 6.00 & {$[2.00]$} & $5.79 \pm 1.22$ & -1.588 & 0.11 \\
\hline Engagement & 6.00 & {$[2.00]$} & $5.65 \pm 1.32$ & 6.00 & {$[2.00]$} & $5.95 \pm 1.22$ & -1.041 & 0.29 \\
\hline Contribution to the well-being of others & 6.00 & {$[2.00]$} & $5.72 \pm 1.27$ & 6.00 & {$[2.00]$} & $5.89 \pm 0.93$ & -0.248 & 0.81 \\
\hline Competence & 6.00 & {$[2.00]$} & $5.87 \pm 1.18$ & 6.00 & {$[0.00]$} & $6.00 \pm 0.74$ & -0.095 & 0.92 \\
\hline Self-acceptance & 6.00 & [2.00] & $5.80 \pm 1.27$ & 6.00 & [2.00] & $5.95 \pm 0.97$ & -0.163 & 0.87 \\
\hline Optimism & 6.00 & [2.00] & $5.59 \pm 1.62$ & 6.00 & {$[1.00]$} & $6.11 \pm 0.89$ & -0.798 & 0.42 \\
\hline Being respected & 6.00 & {$[1.00]$} & $5.90 \pm 1.12$ & 6.00 & {$[1.00]$} & $6.16 \pm 0.68$ & -0.564 & 0.57 \\
\hline Overall FS & 47.00 & [9.00] & $45.12 \pm 8.78$ & 46.00 & {$[7.00]$} & $47.10 \pm 6.01$ & -0.528 & 0.59 \\
\hline
\end{tabular}

$I Q R$, interquartile range.

from the same sample. Cronbach's alpha was used for examining internal consistency. Values $>0.9$ are graded as excellent, $>0.8$ as good, more than 0.70 as acceptable, and $>0.6$ as questionable (George, 2003). Additionally, the intraclass correlation coefficient (ICC) was used to examine the reliability. ICC values $>0.75$ indicate excellent agreement, in the range $0.60-0.74$ indicate good agreement, in the range $0.40-0.59$ show fair to moderate agreement, and $<0.40$ indicate poor agreement (Hutcheson and Sofroniou, 1999; McDowell, 2006).

\section{RESULTS}

A total of 130 participants were recruited for the present study out of which $85.4 \%$ were males. The median age of the participant was 28.50 years with an IQR [24.75-32.00]. Approximately $31.54 \%$ of participants reported having a postgraduate education [ 18 years of education], followed by $30.77 \%$ of participants having a secondary level education [12 years of education]. Among the participants, $67.69 \%$ were Punjabi, and $20.77 \%$ were Pashtoon, as shown in Table 1. However, all the ethnic groups do understand and speak Urdu as it is the national language of Pakistan.

\section{Construct Validity (Factor Analysis) Confirmatory Factor Analysis (CFA)}

CFA was performed to validate the proposed model. Overall, the goodness of fit was evaluated by examining numerous fit indices. The fit indices used to examine this model were the chi square $\left(\chi^{2}\right)$, comparative fit index (CFI), $p$ of close fit (PCLOSE), and root-mean-square error of approximation (RMSEA). Browne and Cudeck (1993) specify the cut-off criteria for CFI as $>0.90$. For relative $\chi^{2}$, cut-off criteria vary from a higher value of 5.0 (Wheaton et al., 1977) to a lower value of 2.0 (Tabachnick and Fidell, 2007). For RMSEA, the cut-off lies at $<0.06-0.08$ (Schreiber et al., 2006).

CFA for the FS scale was carried out with all eight items (Figure 1). The analysis revealed that the model came out as bad fit as indices indicated: $\chi^{2}=2.34, p=0.001$, CFI $=0.95$, RMSEA $=0.102$, and PCLOSE $=0.01$. Factor loadings revealed that item 8-"People respect me"-had a factor loading of 0.62 , which is comparatively lower than other factor loadings. A
TABLE 3 | Scores of the participants at the test (baseline) and retest of the Urdu FS.

\begin{tabular}{|c|c|c|c|c|c|}
\hline \multirow[t]{2}{*}{ Domains } & \multicolumn{2}{|c|}{ Test $(n=130)$} & \multicolumn{2}{|c|}{$\begin{array}{l}\text { Retest } \\
(n=119)\end{array}$} & \multirow{2}{*}{$\begin{array}{c}\begin{array}{c}\text { Mann- } \\
\text { Whitney } \\
U \text {-test }\end{array} \\
p \text {-value }\end{array}$} \\
\hline & Median & IQR & Median & [IQR] & \\
\hline Purpose and meaning & 6.00 & [2.00] & 6.00 & {$[1.00]$} & 0.99 \\
\hline Supportive relationships & 6.00 & {$[1.00]$} & 6.00 & {$[2.00]$} & 0.2 \\
\hline Engagement & 6.00 & [2.00] & 6.00 & [2.00] & 0.99 \\
\hline $\begin{array}{l}\text { Contribution to the well-being } \\
\text { of others }\end{array}$ & 6.00 & [2.00] & 6.00 & {$[2.00]$} & 0.97 \\
\hline Competence & 6.00 & {$[1.00]$} & 6.00 & [2.00] & 0.13 \\
\hline Self-acceptance & 6.00 & [2.00] & 6.00 & [2.00] & 0.68 \\
\hline Optimism & 6.00 & [2.00] & 6.00 & [2.00] & 0.85 \\
\hline Being respected & 6.00 & {$[1.00]$} & 6.00 & {$[1.00]$} & 0.70 \\
\hline Overall FS & 47.00 & {$[9.00]$} & 47.00 & [10.00] & 0.88 \\
\hline
\end{tabular}

$I Q R$, interquartile range.

lower factor loading on this item indicates that item 8 does not represent the latent variable "flourishing" fully. Therefore, this was considered to be the reason of a bad-fit model. No indices were modified for the initial run. However, to improve the model and retain item 8 , indices were modified, but the model revealed similar results as explained above. Figure 1 shows the model fit with item 8.

To improve the model fit, CFA was performed again (Figure 2) but with item 8 removed owing to its lower loading. The analysis now revealed a good-fit model as indicated by indices:

$\chi^{2}=1.64, p=0.06, \mathrm{CFI}=0.98, \mathrm{RMSEA}=0.07$, and PCLOSE $=0.23$.

The CFA indicated that the original model could not be confirmed and modifications had to be made to obtain a good-fit model.

\section{Exploratory Factor Analysis}

This analysis revealed that the Urdu FS had 1-factor loadings based on principal component analysis with varimax rotation, 
TABLE 4 | The psychometric properties of the FS.

\begin{tabular}{|c|c|c|c|c|c|c|}
\hline \multirow[t]{2}{*}{ Domain } & \multirow[t]{2}{*}{$\begin{array}{l}\text { Cronbach's alpha for } \\
\text { overall instrument }\end{array}$} & \multirow[t]{2}{*}{$\begin{array}{l}\text { Corrected item } \\
\text { total correlation }\end{array}$} & \multirow[t]{2}{*}{$\begin{array}{l}\text { Cronbach alpha if } \\
\text { item deleted }\end{array}$} & \multirow{2}{*}{$\frac{\text { Test }(n=130)}{\text { Median }}$} & \multirow{2}{*}{$\begin{array}{c}\begin{array}{c}\text { Retest } \\
(n=119)\end{array} \\
\text { Median }\end{array}$} & \multirow[t]{2}{*}{$\begin{array}{l}\text { Intraclass correlation } \\
\text { coefficient }(\text { ICC })^{\star}\end{array}$} \\
\hline & & & & & & \\
\hline Purpose and meaning & 0.914 & 0.682 & 0.909 & 6.00 & 6.00 & $0.99^{\star}$ \\
\hline Supportive relationships & & 0.739 & 0.901 & 6.00 & 6.00 & $0.61^{*}$ \\
\hline Engagement & & 0.770 & 0.899 & 6.00 & 6.00 & $0.98^{*}$ \\
\hline $\begin{array}{l}\text { Contribution to the well-being of } \\
\text { others }\end{array}$ & & 0.724 & 0.903 & 6.00 & 6.00 & $0.99^{\star}$ \\
\hline Competence & & 0.794 & 0.898 & 6.00 & 6.00 & $0.40^{\star}$ \\
\hline Self-acceptance & & 0.793 & 0.897 & 6.00 & 6.00 & $0.97^{\star}$ \\
\hline Optimism & & 0.671 & 0.908 & 6.00 & 6.00 & $0.99^{*}$ \\
\hline Being respected & & 0.661 & 0.908 & 6.00 & 6.00 & $0.99^{*}$ \\
\hline
\end{tabular}

*Statistically significant at $p<0.05$.

this shows that with $64.037 \%$ of the variance $[\mathrm{KMO}=0.915$, chi-square $=637.687$, Bartlett's test of sphericity was significant $(d f=28, p<0.001)]$.

The Mann-Whitney $U$-test was used to determine whether the Urdu FS was able to discriminate between males and females from the same sample. The significance level was set at $p<0.05$. The overall score of the FS, as well as for each domain, was somewhat better for female participants $(47.10 \pm 6.01)$ compared to males $(45.12 \pm 8.78)$. However, the differences were not statistically significant (Table 2).

Discriminative validity was assessed using the Mann-Whitney $U$-test to determine if there was no significant difference between test-retest reliability scores. The median scores for the FS for all the domains at baseline $(n=130)$ and retest $(n=119)$ are shown in the table below. The table shows similar interpretation of responses by participants at baseline and retest. The scale is therefore stable, as shown in Table 3. The Mann-Whitney $U$ test was used in this study because the aim was to compare two sample means of the same population (i.e., males and females and test-retest reliability scores).

The overall Cronbach's alpha for the Urdu FS was 0.914. For retest, 11 participants did not show up owing to personal reasons and busy schedules, and they were dropped for the follow-up. The ICC at test-retest for all domains were statistically significant $(p<0.001)$ and showed excellent agreement for all items (Table 4).

\section{DISCUSSION}

This is the first study to evaluate the construct validity and reliability of the Flourishing Scale in Urdu in a sample of 130 adults. Findings from the exploratory analysis support the unidimensionality of this scale. Our study also examined the retest reliability at a time interval of 1 month, similar to the study carried out by Diener et al. in 1999 (Keyes et al., 2008).

Like the previous versions of the FS (Diener et al., 2010; Hone et al., 2013; Silva and Caetano, 2013), the Urdu FS has shown adequate reliability (Henson, 2001). The present research study also helps fill the knowledge and research gaps and would ease future research studies on samples understanding the Urdu language. Findings of the current study are in harmony with the results of past research (Ryff, 1989; Diener and Biswas-Diener, 2008; Seligman, 2011). This study has added evidence pertaining to the dimensionality and assessment of flourishing.

However, of note, in CFA, an item designed to measure "social relationships" (i.e., item \# 8: "People respect me") as a component of flourishing was supported to be discarded. The conceptualization of flourishing by Keyes (2007), Forgeard et al. (2011), and Huppert and So (2013) do not consider the observed variable "social relationships" through the respect from others in the operationalization of the latent variable "flourishing." Therefore, it can be assumed that weak theoretical justification may be the reason for the lower factor loading on item 8 (i.e., "People respect me"), which resulted in the removal of this item to improve the goodness of fit. Furthermore, the cultural difference between the current Pakistani sample and the original sample may have played a role in the lower factor loadings. Variation in conceptualization can induce differences in the prevalence of a construct (Hone et al., 2014) across cultures. Therefore, it can be argued that some items may not fully represent the said construct in a culture, resulting in the suggested removal of those items. Further research is strongly suggested to explore about this possibility.

Regarding the presence of gender differences in the FS, mixed evidence exists. Some studies have shown the presence of gender differences (Howell and Buro, 2014), whereas others have shown the absence of any differences due to gender (Diener et al., 2010). In harmony with the study conducted by Diener et al. (2010), our study also did not find any significant gender differences (Diener et al., 2010), although some caution is recommended when interpreting this result considering the significantly smaller number of females than males in the current sample. Small but non-significant gender differences in our study can be supported by the study of Arrosa and Gandelman (2016). According to Arrosa and Gandelman (2016), all around the world, females are found to be happier (Arrosa and Gandelman, 2016).

Although the tool was translated into Urdu in some previous research studies, it was uncertain whether such studies have 
established the psychometric properties of the Urdu version of the FS. Thus, the current study helped fill the research gap and presented some evidence regarding the application of the FS (Diener et al., 2010) in a sample of Pakistani adults and may permit the findings to be better generalized to Pakistani people from varying backgrounds. This could help facilitate the future comparison of well-being of people from social groups with different ages and social status. Greater cross-cultural studies of eudaimonic well-being would be beneficial in the literature and could help facilitate the conceptual understanding of this complex construct.

In harmony with the original English version of the FS (Diener et al., 2010), we found that the Urdu version of the FS showed a high internal consistency reliability $(\alpha=0.914)$ with a significant ICC ( $p<0.001)$ (Nunnally and Bernstein, 1994; Henson, 2001). In our study, the KMO value was 0.915 with a chi-square value $\chi^{2}$ of 637.687, and the Bartlett's test of sphericity was significant $(d f=28, p<0.001)$. The ICC at test-retest for all domains was statistically significant $(p<0.001)$ and showed excellent agreement for all items. As the English version of the FS did not assess the ICC, we were not able to compare our ICC results with that of the previous studies. In addition, the discriminative validity established no significant changes in test (baseline) and retest results. We were not able to compare our results with the results obtained with the English version of the FS, as discriminative validity was not assessed.

In a nutshell, it can be said that the aim of this study was achieved and results have demonstrated that the Urdu version of the FS has good psychometric properties resembling those verified in the original study (Diener et al., 2010). This version of the FS has also shown excellent reliability and good factorial validity. The CFA revealed the good-fit model for seven items and one item (Item 8) was discarded. However, in future studies, the psychometric properties of the Urdu version of the FS should be assessed in other cohorts, for instance adolescents. In addition, the Urdu FS should be correlated with other instruments and scales of subjective and psychological well-being, such as the Personal Wellbeing Index (Group, 2006), the Basic Needs Satisfaction Scale (Ryan and Deci, 2001), and the Ryff's scales of Psychological Well-being (Ryff and Keyes, 1995).

\section{LIMITATIONS}

The strength of our study is that this tool was translated and validated in Urdu to access flourishing/well-being in the Pakistani population, addressing a gap in the literature. One

\section{REFERENCES}

Arrosa, M. L., and Gandelman, N. (2016). Happiness decomposition: female optimism. J. Happiness Stud. 17, 731-756. doi: 10.1007/s10902-015-9618-8

BBC (2014). Languages - Urdu - A Guide to Urdu - 10 Facts About the Urdu Language. Available online at: http://www.bbc.co.uk/languages/other/urdu/ guide/facts.shtml

Bech, P. (1999). Health-related quality of life measurements in the assessment of pain clinic results. Acta Anaesthesiol. Scand. 43, 893-896. doi: 10.1034/j.1399-6576.1999.430906.x limitation of the study was geographical, as the data were collected from only one city due to convenience sampling. Another limitation of this study was the non-balanced gender sample, as only a small sample of females was recruited; a more balanced gender sample would have given more representative findings. In addition, our sample in this study was based on a higher educated population than the mean in the country. Furthermore, considering the cross-sectional design of this study, a small sample size, and the limited measure available to assess the aspects of concurrent validity, further studies on larger and gender-balanced samples are required for a greater depth of validation of the Urdu version of the FS.

\section{CONCLUSION}

The Urdu version FS is suggested as a valid and reliable measure for assessing subjective well-being among the Pakistani population. The validated Urdu FS tool can be used in clinical psychology and positive psychology studies to access well-being. However, future research is strongly recommended to continue to assess the scale reliability and validity in more subpopulations and in more depth.

\section{ETHICS STATEMENT}

This study was approved by the ethics committee of the Abasyn University in Peshawar, Pakistan.

\section{AUTHOR CONTRIBUTIONS}

FRC and KM collected and analyzed the data and prepared the manuscript. KG supervised the whole process and approved the final version of the manuscript to be published and also helped in proofreading and providing technical psychological insights. $\mathrm{NB}, \mathrm{AK}$, and YA-W helped in revising the manuscript and contributed into the result and method sections and also helped in performing the statistical analysis. TMK, IUR, FRC, KM, BA, MAA, MA, FB, and YK helped in performing the statistical analysis, revising the analysis and checking and drafting of the results section. KG, NB, AK, YA-W, BA, MAA, MA, FB, and YK helped in running the Confirmatory Factor Analysis, checked the Exploratory Factor Analysis and interpreted the data. Moreover, they also played a significant role in revising the manuscript after peer review. All the current and new authors approved the final version of the manuscript to be published.

Bradburn, N. M. (1969). The Structure of Psychological Well-being. Chicago, Aldine Pub. Co.

Browne, M. W., and Cudeck, R. (1993). "Alternative ways of assessing model fit," in Testing Structural Equation Models, eds K. A. Bollen and J. S. Long (Newbury Park, CA: Sage), 136-162.

Busseri, M. A., and Sadava, S. W. (2011). A review of the tripartite structure of subjective well-being: implications for conceptualization, operationalization, analysis, and synthesis. Pers. Soc. Psychol. Rev. 15, 290-314. doi: 10.1177/10888683103 91271 
Checa, I., Perales, J., and Espejo, B. (2017). Spanish validation of the Flourishing Scale in the general population. Curr. Psychol. 1-8. doi: 10.1007/s12144-017-9581-0. Available online at: https://www. researchgate.net/profile/Irene_Esquiva/publication/315056190_Spanish_ Validation_of_the_Flourishing_Scale_in_the_General_Population/links/ $5 \mathrm{a} 28 \mathrm{e} 20 \mathrm{e} 4585155 \mathrm{dd} 42782 \mathrm{c} 0 /$ Spanish-Validation- of-the-Flourishing-Scalein-the-General-Population.pdf

Corey Lee, M. K. (1998). Social well-being. Soc. Psychol. Q. 61, 121-140. doi: $10.2307 / 2787065$

Diener, E. (1984). Subjective well-being. Psychol. Bull. 95, 542-575. doi: $10.1037 / 0033-2909.95 .3 .542$

Diener, E., and Biswas-Diener, R. (2008). Happiness: Unlocking the Mysteries of Psychological Wealth. Malden, MA: John Wiley \& Sons.

Diener, E., Emmons, R. A., Larsen, R. J., and Griffin, S. (1985). The Satisfaction with Life Scale. J. Pers. Assess. 49, 71-75. doi: 10.1207/s15327752jpa 4901_13

Diener, E., Kesebir, P., and Lucas, R. (2008). Benefits of accounts of well-being-for societies and for psychological science. Appl. Psychol. 57, 37-53. doi: 10.1111/j. 1464-0597.2008.00353.x

Diener, E., Suh, E. M., Lucas, R. E., and Smith, H. L. (1999). Subjective well-being: three decades of progress. Psychol. Bull. 125, 276-302. doi: $10.1037 / 0033-2909.125 .2 .276$

Diener, E., Wirtz, D., Biswas-Diener, R., Tov, W., Kim-Prieto, C., Choi, D. W., et al. (2009). "New measures of well-being," in Assessing Well-Being, ed E. Diener (Dordrecht; New York, NY: Springer), 247-266.

Diener, E., Wirtz, D., Tov, W., Kim-Prieto, C., Choi, D. W., Oishi, S., et al. (2010). New well-being measures: Short Scales to assess flourishing and positive and negative feelings. Soc. Ind. Res. 97, 143-156. doi: 10.1007/s11205-0099493-y

Duan, W., and Xie, D. (2016). Measuring adolescent flourishing: psychometric properties of Flourishing Scale in a sample of Chinese adolescents. J. Psychoeduc. Assess. 1-5. doi: 10.1177/0734282916655504

Esch, T., Jose, G., Gimpel, C., Von Scheidt, C., and Michalsen, A. (2013). [The Flourishing Scale (FS) by Diener et al. is now available in an authorized German version (FS-D): application in mind-body medicine]. Forsch Komplement. 20, 267-275. doi: 10.1159/000354414

Field, A. P. (2009). Discovering Statistics Using SPSS, 3rd Edn. Los Angeles, CA; London: Sage Publications.

Forgeard, M. J. C., Jayawickreme, E., Kern, M. L., and Seligman, M. E. P. (2011). Doing the right thing: measuring wellbeing for public policy. Int. J. Wellbeing 1, 79-106. doi: 10.5502/ijw.vli1.15

George, D. M. P. (2003). SPSS for Windows Step by Step: A Simple Guide and Reference. 11.0 update. Reference and Research Book News 17 (Boston, MA: Allyn \& Bacon).

Giuntoli, L., Ceccarini, F., Sica, C., and Caudek, C. (2017). Validation of the Italian versions of the Flourishing Scale and of the scale of positive and negative experience. SAGE Open 7, 1-12. doi: 10.1177/2158244016682293

Group, I. W. (2006). Personal Wellbeing Index. Melbourne, Australian Centre on Quality of Life: School of Psychology, Deakin University. Available online at: http://www.deakin.edu.au.ezproxy.lib.monash.edu.au/research/acqol/ instruments/wellbeing-index/pwi-a-english.pdf (Accessed November 3, 2017).

Guillemin, F., Bombardier, C., and Beaton, D. (1993). Cross-cultural adaptation of health-related quality of life measures: literature review and proposed guidelines. J. Clin. Epidemiol. 46, 1417-1432. doi: 10.1016/0895-4356(93)90142-N

Henson, R. K. (2001). Understanding internal consistency reliability estimates: a conceptual primer on coefficient alpha. Measur. Evalu. Couns. Dev. 34, 177-189. Available online at: https://search.proquest.com/openview/ b656773741efd5cla7c4e8133fdd8439/1?pq- origsite=gscholar $\& \mathrm{cbl}=34423$

Hills, P., and Argyle, M. (2002). The Oxford Happiness Questionnaire: a compact scale for the measurement of psychological well-being. Pers. Individ. Diff. 33, 1073-1082. doi: 10.1016/S0191-8869(01)00213-6

Hojabrian, H., Rezaei, A. M., Bigdeli, I., Najafi, M., and Mohammadifar, M. A. (2018). Construction and Validation of the Human Psychological Flourishing Scale (HPFS) in sociocultural context of Iran. Pract. Clin. Psychol. 6, 129-139. doi: $10.29252 /$ nirp.jpcp.6.2.129
Hone, L., Jarden, A., and Schofield, G. (2013). Psychometric properties of the Flourishing Scale in a New Zealand sample. Soc. Ind. Res. 119, 1031-1045. doi: 10.1007/s11205-013-0501-x

Hone, L. C., Jarden, A., Schofield, G. M., and Duncan, S. (2014). Measuring flourishing: the impact of operational definitions on the prevalence of high levels of wellbeing. Int. J. Wellbeing 4, 62-90. doi: 10.5502/ijw.v4i1.4

Howell, A. J., and Buro, K. (2014). Measuring and predicting student wellbeing: further evidence in support of the Flourishing Scale and the scale of positive and negative experiences. Soc. Ind. Res. 121, 903-915. doi: 10.1007/s11205-014-0663-1

Huppert, F. A., and So, T. C. (2013). Flourishing across Europe: application of a new conceptual framework for defining well-being. Soc. Ind. Res. 110, 837-861. doi: 10.1007/s11205-011-9966-7

Hutcheson, G. D., and Sofroniou, N. (1999). The Multivariate Social Scientist: Introductory Statistics Using Generalized Linear Models. London:Sage.

Kaiser, H. F. (1974). An index of factorial simplicity. Psychometrika 39, 31-36. doi: 10.1007/BF02291575

Keyes, C. L. (2002). The mental health continuum: from languishing to flourishing in life. J. Health Soc. Behav. 43, 207-222. doi: 10.2307/ 3090197

Keyes, C. L. (2005). Mental illness and/or mental health? Investigating axioms of the complete state model of health. J. Consult. Clin. Psychol. 73, 539-548. doi: 10.1037/0022-006X.73.3.539

Keyes, C. L. (2007). Promoting and protecting mental health as flourishing: a complementary strategy for improving national mental health. Am. Psychol. 62, 95-108. doi: 10.1037/0003-066X.62.2.95

Keyes, C. L., Wissing, M., Potgieter, J. P., Temane, M., Kruger, A., and Van Rooy, S. (2008). Evaluation of the mental health continuum-short form (MHC-SF) in setswana-speaking South Africans. Clin. Psychol. Psychother. 15, 181-192. doi: $10.1002 /$ cpp. 572

Lai, B. P., Chung, T. K., Lee, D. T., Kong, G. W., and Lok, I. H. (2013). Measuring grief following miscarriage: psychometric properties of the Chinese version of the Perinatal Grief Scale. Assessment 20, 123-129. doi: 10.1177 1073191110397275

Lee, G. R., and Ishii-Kuntz, M. (1987). Social interaction, loneliness, and emotional well-being among the elderly. Res. Aging 9, 459-482. doi: 10.1177/ 0164027587094001

Lyubomirsky, S., and Lepper, H. S. (1999). A measure of subjective happiness: preliminary reliability and construct validation. Soc. Ind. Res. 46, 137-155 doi: 10.1023/A:1006824100041

McDowell, I. (2006). Measuring Health: A Guide to Rating Scales and Questionnaires. New York, NY: Oxford University Press.

Nunnally, J. C., and Bernstein, I. H. (1994). Psychometric Theory. New York, NY: McGraw-Hill.

Ramírez-Maestre, C., Correa, M., Rivas, T., López-Martínez, A. E., SerranoIbáñez, E. R., and Esteve, R. (2017). Psychometric characteristics of the Flourishing Scale-Spanish Version (FS-SV). The factorial structure in two samples: students and patients with chronic pain. Pers. Individ. Diff. 117, 30-36. doi: $10.1016 /$ j.paid.2017.05.035

Ryan, R. M., and Deci, E. L. (eds.) (2001). To Be Happy or to be Self-fulfilled: A Review of Research on Hedonic and Eudaimonic Well-being. Palo Alto, CA: Annual Reviews/Inc.

Ryff, C. D. (1989). Happiness is everything, or is it? Explorations on the meaning of psychological well-being. J. Pers. Soc. Psychol. 57:1069. doi: $10.1037 / 0022-3514.57 .6 .1069$

Ryff, C. D., and Keyes, C. L. (1995). The structure of psychological wellbeing revisited. J. Pers. Soc. Psychol. 69, 719-727. doi: 10.1037/0022-3514.69. 4.719

Schimmack, U., Diener, E., and Oishi, S. (2002). Life-satisfaction is a momentary judgment and a stable personality characteristic: the use of chronically accessible and stable sources. J. Pers. 70, 345-384. doi: 10.1111/1467-6494.05008

Schotanus-Dijkstra, M., ten Klooster, P. M., Drossaert, C. H. C., Pieterse, M. E., Bolier, L., Walburg, J. A., et al. (2016). Validation of the Flourishing Scale in a sample of people with suboptimal levels of mental well-being. BMC Psychol. 4:12. doi: $10.1186 / s 40359-016-0116-5$ 
Schreiber, J. B., Nora, A., Stage, F. K., Barlow, E. A., and King, J. (2006). Reporting structural equation modeling and confirmatory factor analysis results: a review. J. Educ. Res. 99, 323-338. doi: 10.3200/JOER.99.6.323-338

Seligman, M. E. P. (2011). Flourish: A Visionary Understanding of Happiness and Well-being. New York, NY: Free Press.

Silva, A. J., and Caetano, A. (2013). Validation of the flourishing scale and scale of positive and negative experience in Portugal. Soc. Ind. Res. 110, 469-478. doi: 10.1007/s11205-011-9938-y

Singh, K., Junnarkar, M., and Jaswal, S. (2017). Validating the Flourishing Scale and the scale of positive and negative experience in India. Mental Health Relig. Cult. 19, 943-954, doi: 10.1080/13674676.2016. 1229289

Sumi, K. (2014). Reliability and validity of Japanese versions of the Flourishing scale and the scale of positive and negative experience. Soc. Ind. Res. 118, 601-615. doi: 10.1007/s11205-013-0432-6

Tabachnick, B. G., and Fidell, L. S. (2007). Using Multivariate Statistics. Boston, MA: Allyn and Bacon.

Tang, X., Duan, W., Wang, Z., and Liu, T. (2016). Psychometric evaluation of the simplified chinese version of Flourishing Scale. Res. Soc. Work Pract. 26, 591-599. doi: 10.1177/1049731514557832

Tennant, R., Hiller, L., Fishwick, R., Platt, S., Joseph, S., Weich, S., et al. (2007). The Warwick-Edinburgh Mental Well-being Scale (WEMWBS): development and UK validation. Health Qual. Life Outcomes 5:63. doi: 10.1186/14777525-5-63

Tong, K. K., and Wang, Y. Y. (2017). Validation of the flourishing scale and scale of positive and negative experience in a Chinese community sample. PLOS ONE 12:e0181616. doi: 10.1371/journal.pone. 0181616
Vujčić, M. T., Lipovčan, L. K., Larsen, Z. P., Brajša-Žganec, A., and Franc, R. (2017). "Flourishing in Croatia: the validation of the croatian versions of the Flourishing Scale and the scale of positive and negative experience," in A World to Win: European Happiness Days (Rotterdam, Netherlands).

Watson, D., Clark, L. A., and Tellegen, A. (1988). Development and validation of brief measures of positive and negative affect: the PANAS scales. J. Pers. Soc. Psychol. 54, 1063-1070. doi: 10.1037/0022-3514.54.6.1063

Wheaton, B., Muthén, B., Alwin, D. F., and Summers, G. F. (1977). Assessing reliability and stability in panel models. Sociol. Methodol. 8, 84-136. doi: 10. $2307 / 270754$

Wild, D., Grove, A., Martin, M., Eremenco, S., Mcelroy, S., Verjee-Lorenz, A., et al. (2005). Principles of good practice for the translation and cultural adaptation Process for Patient-Reported Outcomes (PRO) measures: report of the ISPOR task force for translation and cultural adaptation. Val. Health 8, 94-104. doi: 10.1111/j.1524-4733.2005.04054.x

Conflict of Interest Statement: The authors declare that the research was conducted in the absence of any commercial or financial relationships that could be construed as a potential conflict of interest.

Copyright (c) 2018 Choudhry, Al-Worafi, Akram, Ahmed, Anwar ul Haq, Khan, Rehman, Barki, Munawar, Kamal, Kassab, Bakrin and Golden. This is an openaccess article distributed under the terms of the Creative Commons Attribution License (CC BY). The use, distribution or reproduction in other forums is permitted, provided the original author(s) and the copyright owner(s) are credited and that the original publication in this journal is cited, in accordance with accepted academic practice. No use, distribution or reproduction is permitted which does not comply with these terms. 


\section{APPENDIX}

\section{English FS}

Below are 8 statements with which you may agree or disagree. Using the 1-7 scale below, indicate your agreement with each item by indicating that response for each statement. Kindly place a check mark in the appropriate boxes:

$\begin{array}{lllllll}\begin{array}{l}\text { Strongly } \\ \text { disagree }\end{array} & \text { Disagree } & \begin{array}{l}\text { Slightly } \\ \text { disagree }\end{array} & \begin{array}{l}\text { Neither agree } \\ \text { nor disagree }\end{array} & \begin{array}{l}\text { Slightly } \\ \text { agree }\end{array} & \text { Agree } & \begin{array}{l}\text { Strongly } \\ \text { agree }\end{array}\end{array}$

1. I lead a purposeful and meaningful life.

2. My social relationships are supportive and rewarding.

3. I am engaged and interested in my daily activities.

4. I actively contribute to the happiness and well-being of

others.

5. I am competent and capable in the activities that are important to me.

6. I am a good person and live a good life.

7. I am optimistic about my future.

8. People respect me. 
Urdu Version of FS

مندرج ذيل 8 بيانات درج بيل جن سـح آب اتفاق يا اختلاف كر سكتح بيل نيجه ديا كيا صفر

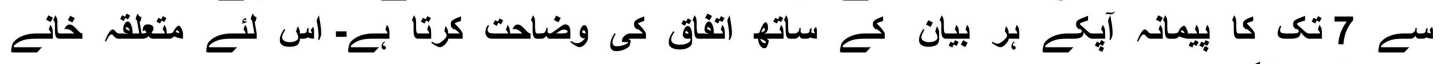

\begin{tabular}{|c|c|c|c|c|c|c|c|c|}
\hline اتفاق & اتفاق & تجنه & نَ & حد" تجه & اختلاف & مكتلاف & & \\
\hline & & & & & & & زبون اربى كز بـ مقصد ربا & 1 \\
\hline & & & & & & & مديركار اور سماجى تعلقات مند مند & 2 \\
\hline & & & & & & & 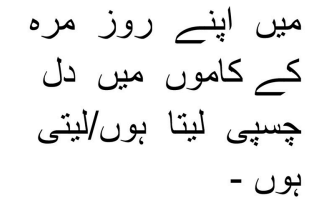 & 3 \\
\hline & & & & & & & 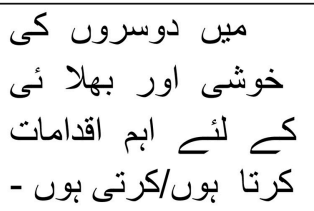 & 4 \\
\hline & & & & & & & 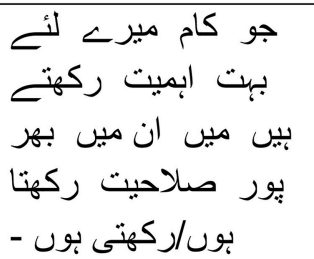 & 5 \\
\hline & & & & & & & 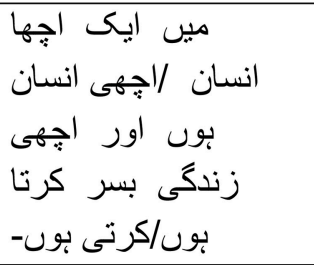 & 6 \\
\hline & & & & & & & 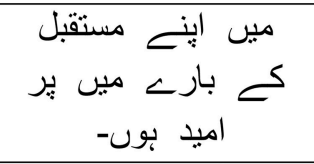 & 7 \\
\hline & & & & & & & لوى ميرى عزت بي- & 8 \\
\hline
\end{tabular}

